\title{
Application of recycled aggregates to the road base mixtures with foamed bitumen in the cold recycling technology
}

\author{
Marek Iwański, Anna Chomicz-Kowalska \\ Kielce University of Technology, Al. Tysiąclecia Państwa Polskiego 7, 25-314 Kielce, Poland
}

\begin{abstract}
To reduce the energy consumption and $\mathrm{CO}_{2}$ emissions during asphalt production, several environmentally friendly technologies have been developed during the last years. One of these technologies is the cold recycling by using foamed bitumen. Foaming the bitumen reduces the binder viscosity temporarily and increases the volume as well. Homogenous foams are produced by injection of cold water into hot bitumen. The paper presents the results of laboratory testing of the physical and mechanical parameters of the recycled material using the foamed bitumen and resistance to the action of water. The tests were performed on the road base mixtures incorporating reclaimed asphalt pavement (RAP) with foamed bitumen. The aim of the tests was to evaluate the properties of the mixes in terms of the recycled aggregates. The mixes included aggregates from the recycling of the crushed stone base layer and from the crushed concrete rubble. The effects of the type of recycled aggregate and amount of foamed bitumen on the air void content, Marshall stability and flow of the recycled mixtures were investigated. Indirect tensile stiffness modulus (ITSM) was determined at temperature $25^{\circ} \mathrm{C}$. Moreover, the detrimental effect of water was measured by comparing indirect tensile strength (ITS soaked and unsoaked) and determine tensile strength retained (TSR) of bitumen stabilized materials. The analysis of the test results allowed to state that if $2.5 \%$ foamed bitumen and $2.0 \%$ of Portland cement are used, the recycled road base had the required physical and mechanical properties and moisture resistance.
\end{abstract}

Keywords: Road base; deep cold recycling; foamed bitumen; Portland cement; moisture susceptibility.

\section{Introduction}

Cold deep recycling with foamed bitumen is used for the processing of a range of mineral materials and reclaimed asphalt or concrete. The old material is recycled either in cold recycling in plant technology, in which it is removed and transported to a mobile plant or in cold recycling in situ technology, in which the existing pavement materials are processed in the recycling machines at the construction site. Currently, an idea of recycling is not only limited to road building, but it is present in many areas of engineering - for example recycling of waste [1].

The bitumen foaming technology has been introduced for the first time by prof Ladis Csanyi and further developed by Mobil Oil in the 1960 [2]. Foamed bitumen is a hot bituminous binder that has been temporarily converted from a liquid state into a foam state by the addition of a small percentage of water and pressurized air [3]. This is mainly a physical rather than a chemical process. The life of the foam at ambient temperature is very short, measured in seconds. Foaming characteristics are affected by bitumen type, grade and by additives [4].

Cold recycling using foamed bitumen provides sustainable, cost-effective and environmentally friendly alternative to the conventional road re-surfacing method with using hot mix asphalt (HMA). Grabowski et al. [5] explained the influence of selected factors on energy consumption during the HMA production and they defined the level of fuel consumption depending on aggregate moisture in relation to the organization of HMA production process. Radziszewski et al. [6] reported that Polish program of construction and re-construction of roads required a large quantity of aggregate. Foamed bitumen can be used to stabilize a variety of materials, including the reclaimed asphalt pavement (RAP) materials. It can be used with recycled and marginal materials and applied as base and sub-base layers in pavements [7]. 


\section{Materials}

\subsection{Foamed bitumen properties}

The foamed bitumen produced on the basis of $85 \mathrm{~N}$ bitumen was used in the lab tests. The following standard and foaming parameters were measured: penetration grade $(P e n)$, breaking point temperature $\left(T_{\text {Fraass }}\right)$, softening point temperature $\left(T_{R \notin B}\right)$, expansion ratio $(E R)$, half-life time $\left(\tau^{1 / 2}\right)$ and foam index $(F I)$. The test results are presented in Table 1.

In this study foamed bitumen was produced using a laboratory mobile foaming plant type WLB 10S, widely used for bitumen foaming properties testing [8], [9] with the following settings:

- temperature of bitumen (before foaming process) $170{ }^{\circ} \mathrm{C}$;

- foaming water content $(F W C) 2.0 \%$;

- air pressure $500 \mathrm{kPa}$;

- water pressure $600 \mathrm{kPa}$.

Table 1. Properties of foamed bitumen

\begin{tabular}{lllllll}
\hline \multicolumn{2}{l}{ Standard parameters } & \multicolumn{5}{l}{ Foaming parameters } \\
\hline $\begin{array}{l}\text { Pen }, 0.1 \mathrm{~mm} \\
(\mathrm{EN} \mathrm{1426)}\end{array}$ & $T_{\text {Fraass }}{ }^{\circ} \mathrm{C}$ & $T_{\text {R\&B, }}{ }^{\circ} \mathrm{C}$ & $F W C, \%$ & ER & $\tau 1 / 2, \mathrm{~s}$ & FI, s \\
\hline 81 & $(\mathrm{EN} \mathrm{12593)}$ & $(\mathrm{EN} \mathrm{1427)})$ & & & & \\
\hline
\end{tabular}

\subsection{Active filler}

Depending on the type of the material being recycled, different active filler can be added. All available binders can be used, cement, hydrated lime, fly ash and the combinations of those at various proportions. As the percentage amount of the binder added is based on the required parameters and the material type, it is specified individually during the mix formulation design. The binder is also intended to complement the fine fractions less than $0.063 \mathrm{~mm}$. According to the Technical Guideline TG2 [10], the cement content in Bitumen Stabilized Materials (BSMs) with foamed bitumen (BSM-foam) and bitumen emulsion (BSM-emulsion) should not exceed of added bitumen quantities. Brown and Needham [11] proved that application of active filler (lime or cement) improves of mechanical parameters of the cold mixes. Similar findings from lab research were reported by Hodginson and Visser [12]. Jian Xu et al. [13] concluded that Portland cement is absolutely necessary to enhance the rate of increase in initial strength and to improve both the moisture resistance and high temperature parameters of BSM-foam mixtures.

A fly ash Portland cement (CEM II/B-V 32,5R meeting the requirements of EN 197-1 standard) was used in this investigations as an active additive.

\subsection{Mix design procedure}

The aim of the laboratory tests was the comparative analysis of mixes with foamed bitumen that differ by the type of the recycled aggregate reclaimed from the existing lower road construction layers. Currently, the deep cold recycling technology using mineral-cement-emulsion (MCE) mixtures (acc. to [14]) is popular in Poland. There is no requirement for foamed bitumen treated materials because this technology is in the development phase. Therefore the mineral recycled mixtures (Fig. 1) satisfied grading criteria for mixes with foamed bitumen according to the South African and German guidelines [10], [15].

In the first mix (Mix-1) the material from the crushed stone road base 0/31.5 grade was used, while in the other (Mix-2) the material from the road base bounded with hydraulic binder (crushed lean concrete). In both mixes the content of RAP $0 / 16 \mathrm{~mm}$ grade material derived from the milling of upper bitumen layers was $48 \%$. Dolomite aggregate $0 / 4 \mathrm{~mm}$ was used as a new material. The bitumen content in the RAP material amounted 5.4\% and was determined using the solvent extraction test according to the European standard EN 12274-2. Recycled aggregates used in this study meet the requirements according to EN 13055-2. Table 2 presents the composition of the mixtures.

The optimum moisture content (OMC) is essential for good dispersion of the foam in the mix. The water, which satisfied the requirements of the standard EN 1008 was used as mixing water in the recycled mineral mixes. During the mixing process, the amount of water added to mixture was approximately ensured $75 \%$ of OMC recommended by the Technical Guidelines [15]. All samples were compacted with 75 blows per side with Marshall hammer. Before mixing of foamed bitumen with the aggregate, the mineral materials were kept in the oven at $25^{\circ} \mathrm{C}$ for two hours, because it is an important factor affecting on the mechanical properties of the foamed bitumen mixes [16]. 


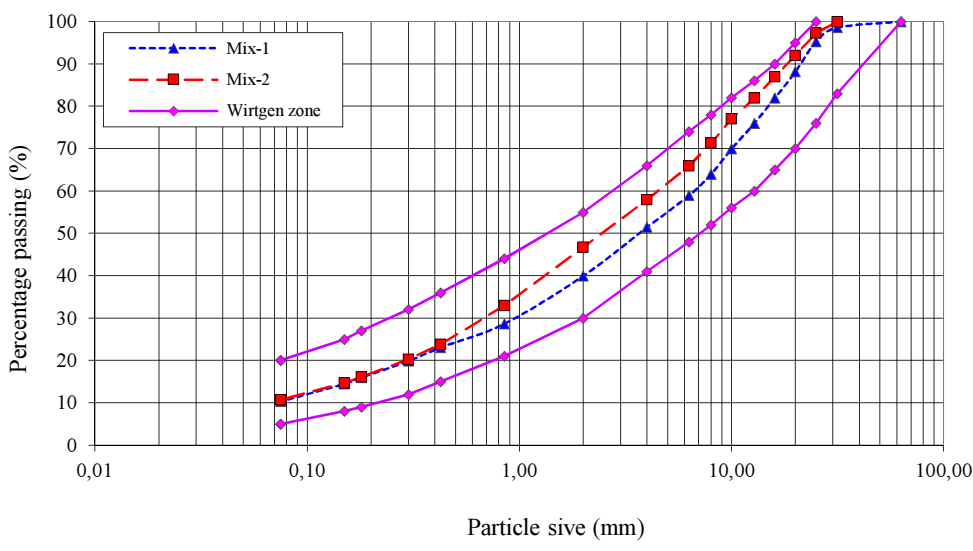

Fig. 1. Particle size distribution in road base mixes with foamed bitumen
Table 2. The compositions of road base mixes

\begin{tabular}{lll}
\hline Components (\%) & Mix-1 & Mix-2 \\
\hline Portland cement & 2.0 & 2.0 \\
\hline RAP & 48 & 48 \\
\hline Recycled aggregate ${ }^{1)}$ & 20 & - \\
\hline Recycled aggregate ${ }^{2)}$ & - & 20 \\
\hline Dolomite aggregate $(0 / 4 \mathrm{~mm})$ & 30 & 30 \\
\hline 1) $0 / 31.5 \mathrm{~mm}$ aggregate size from the recycling of the crushed \\
stone road base \\
2) \\
concrete road base
\end{tabular}

\section{Results and discussion}

\subsection{Experimental program}

The foamed bitumen in both mixes amounted from $2.0 \%$ to $3.5 \%$, with a step of $0.5 \%$. Higher bitumen content results in greater flexibility of mixes but lower resistance to deformation [17], [18]. The Portland cement was used in the amount of $2.0 \%$, which was determined using multicriteria optimization [19], [20]. The use of higher amounts of active filler in BSMfoam may induce excessive stiffness of the base layer which in turn may put the upper layers of the pavement at risk of fatigue and reflective cracking. The cement content is suggested to be limited to $2.0 \%$ to ensure favorable mechanical property and moisture resistance [21].

The aim of the lab tests was to evaluate the properties of the mixes in terms of the recycled aggregates type (crushed stone, crushed lean concrete) and amount of the foamed bitumen $(2.0 \%, 2.5 \%, 3.0 \%, 3.5 \%)$. The scope of the tests included determining the physical, mechanical parameters and moisture sensitivity of the recycled mixes.

The following parameters were analyzed: air void content $\left(V_{m}\right)$, Marshall stability $(S)$ and flow $(F)$, dry and wet indirect tensile strength $\left(I T S_{d r y}, I T S_{w e t}\right)$, tensile strength retained (TSR) and indirect tensile stiffness modulus (ITSM) at $25^{\circ} \mathrm{C}($ IT-CY test configuration). The tests were performed on 9 samples for each foamed bitumen concentration level.

To evaluate the influence of the factors in the experiment domain (type, amount) on the distribution of the analyzed parameters, the significance of impact of both factors was performed using the two-way Analysis of Variance (ANOVA).

\subsection{Air void content tests}

The results of the laboratory tests of the air void content $\left(V_{m}\right)$ with the emphasis on values of the dispersion around the means are presented in Fig. 2. Table 3 presents evaluate the significance impact of the tested factors (type, amount) on the distribution of the analyzed feature, which was performed using the analysis of variance.

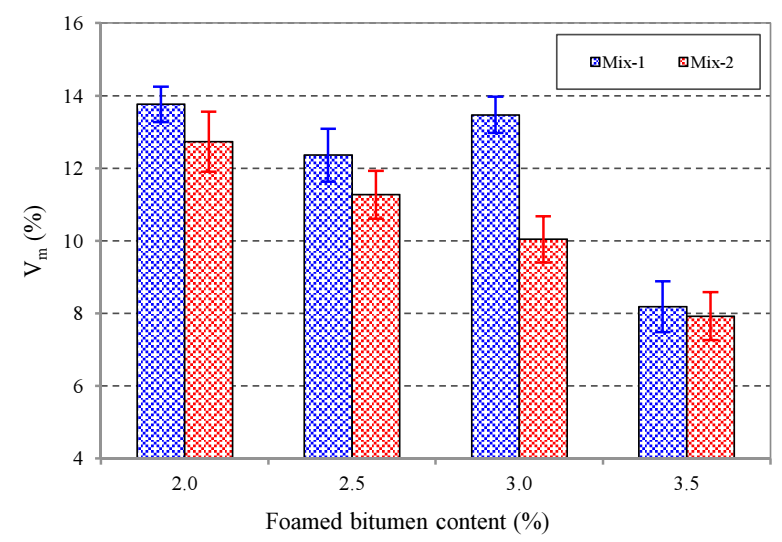

Table 3. Evaluation of significant influence (two-way ANOVA) of the factors (type, amount) on the $V_{m}$ feature

\begin{tabular}{lll}
\hline Source & Type & Amount \\
\hline Degrees of freedom & 1 & 3 \\
Sum of squares & 22.0558681 & 193.704238 \\
Mean of squares & 22.0558681 & 64.5680790 \\
F Ratio & 18.66 & 54.64 \\
p-value & $<0.0001$ & $<0.0001$ \\
\hline
\end{tabular}

Fig. 2. Foamed bitumen content versus air void content in road base mixtures (the error bars represent the standard deviation)

The analysis of the tests results presented in Fig. 2 indicates that the type of the recycled aggregate and the amount of the applied foamed bitumen in the road base mixes exerted an important impact on the tested parameter.

The highest content of air voids at the lowest content of the foamed bitumen was observed in the mix containing the 
reclaimed material from the crushed stone road base. Excessive air voids content in bituminous layers has a negative effect on resistance to fatigue and weather conditions (e.g. action of water) [22]. A lower air void values were recorded for the mixtures containing recycled crushed line concrete. In neither case the maximum allowable value was exceeded, while the mixtures with the highest concentration of the foamed bitumen $(3.5 \%)$ did not achieve the minimum value of this feature (9-16\% acc. to [14] and 10-15\% acc. to [15]). Air void content depends not only on the type of the aggregate produced from the existing road pavement layers but also on the size of particular fractions in the mineral mix, which contributes to the proper filling of the voids and which ensures watertight road base. The presence of higher levels of the gravel fraction results in the reduced levels of the fine fraction responsible for the filling of void spaces between the coarse aggregate grains.

The two-way analysis of variance (Table 3 ) showed that $p$-value for statistic $\mathrm{F}$ for factors type and amount was less ( $p$-value $<0.0001)$ than the assumed significance level $(\alpha=0.05)$. It can then be stated that the kind of the kind of the recycled aggregates and amount of the foamed bitumen in the recycled mixtures had a significant impact on the distribution of the tested parameter.

\subsection{Marshall tests}

The durability of the pavement structure relies heavily on the properties of the road base which provides the relevant load bearing capacity of the pavement structure and must thus be resistant to the detrimental climatic factors (low winter and high summer temperature). The Marshall stability design criterion was used to determine the optimum binder content [23]. Currently the optimum foamed bitumen content should be determined on the basis of the relationship between indirect tensile strength and foamed bitumen content [15].

The evaluation of the recycled aggregate type added to the mixes with foamed bitumen was a significant element of the evaluation of the road base deformation resistance. Figures below present how the foamed bitumen content of the mixes with different types of recycled aggregate affects the resistance to deformation. Figures $3 \mathrm{a}$ and $3 \mathrm{~b}$ illustrate the variations in the Marshall stability $(S)$ and flow $(F)$ respectively. The results of computations performed in the analysis of variance and related to characteristics in respect to the type of the recycled aggregates and the amount of the foamed bitumen used in the mixtures are presented in Table 4. The Marshall stability and flow tests were conducted acc. To EN 12697-34 standard.

(a)

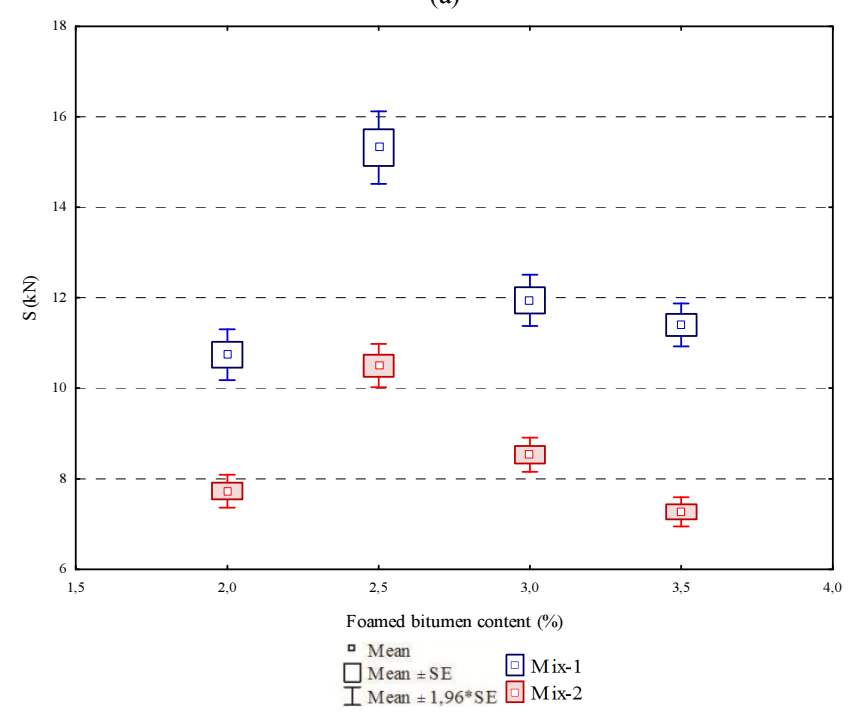

(b)

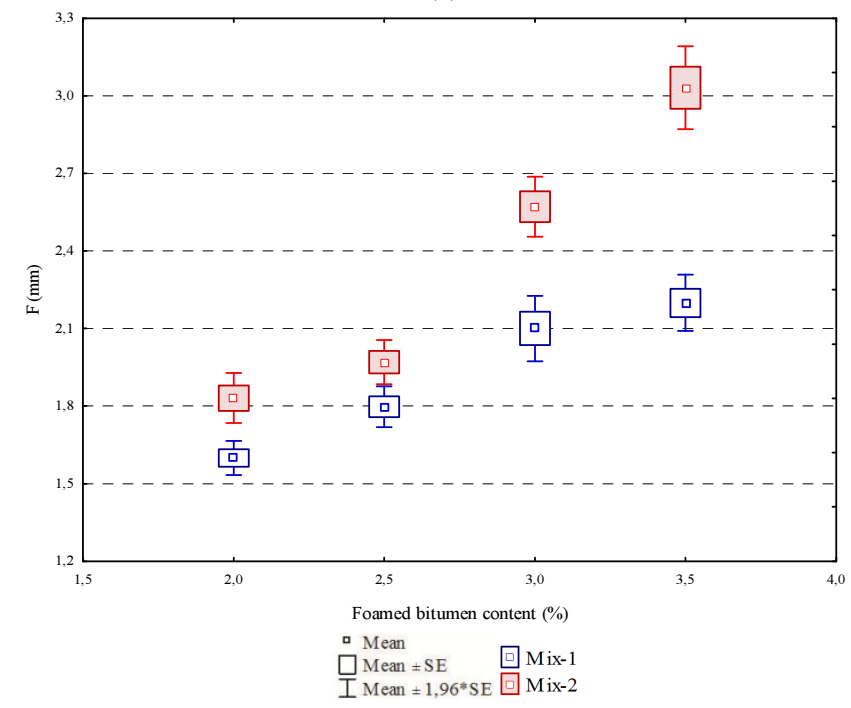

Fig. 3. The impact of the foamed bitumen content on Marshall stability (a) and flow (b)

The results from the tests illustrated in the figures above indicate that the type of the recycled aggregate and the amount of the foamed bitumen in the road base mixes had significant effects on the variation in the Marshall stability and flow.

The results from the tests indicate clearly that the addition of the recycled crushed lean concrete aggregates rises the Marshall stability value in the road base mixes, compared with the mixes containing the crushed stone recycled aggregate. All the mixes with the reclaimed lean concrete had stability values greater than the required value (acc. to [14], $8 \mathrm{kN}$ is the minimum value). The mixes with aggregates produced from the recycled stone base achieved the recommended value only when they contained $2.5 \%$ and $3.0 \%$ foamed bitumen. Both mixes reached maximum stability when the content of the foamed bitumen was $2.5 \%$.

The flow in both mixes varied from $1.6 \mathrm{~mm}$ to $3.03 \mathrm{~mm}$ and fitted in the recommended range of 1.0-3.5 mm (acc. to [14]). Lower flow values were recorded for the mixes with the recycled crushed lean concrete from the existing road base layer. It may be then concluded that the road base with recycled lean concrete aggregate will be more resistant to deformation than the mixes containing the reclaimed stone aggregate. 
Table 4. Analysis of variance (two-way ANOVA) results

\begin{tabular}{lllll}
\hline Feature & $S$ & & $F$ & \\
\hline Source & Type & Amount & Type & Amount \\
\hline Degrees of freedom & 1 & 3 & 1 & 3 \\
Sum of squares & 265.7665125 & 158.7262042 & 3.28106806 & 9.18102639 \\
Mean of squares & 265.7665125 & 52.90873472 & 3.28106806 & 3.06034213 \\
F Ratio & 369.78 & 73.61 & 73.77 & 68.81 \\
$p$-value & $<0.0001$ & $<0.0001$ & $<0.0001$ & $<0.0001$ \\
\hline
\end{tabular}

The $p$-value obtained in the tests for the statistic $\mathrm{F}$ for factors type and amount is definitely lower $(p$-value $<0.0001)$ than the significance level assumed $(\alpha=0.05)$. The null hypothesis must then be rejected with a $5 \%$ error. This means that the kind of the recycled aggregates and content of foamed bitumen in the mixtures affect significantly and to a similar degree the changes of the characteristics being studied.

\subsection{Moisture susceptibility}

According to the guidelines [10], [15] the indirect tensile strength $\left(I T S_{d r y}\right)$ values are determined from the $100 \mathrm{~mm}$ diameter and $63 \mathrm{~mm}$ high specimens after curing time to reach a constant mass. The results obtained after soaking these specimens for 24 hours at $25^{\circ} \mathrm{C}$ are termed $I T S_{w e t}$. The ratio of $I T S_{d r y}$ and ITS $S_{w e t}$, expressed as a percentage, is the Tensile Strength Retained (TSR). This procedure is aimed at evaluating the moisture susceptibility of the bitumen stabilized materials.

Figure 4 shows the influence of the foamed bitumen amount in the recycled mixes with different types of recycled aggregate on variations in the ITS dry and ITS $S_{w e t}$ The results of the tests for the moisture susceptibility on the basis of the TSR evaluation of the recycled road base with foamed bitumen, recycled lean concrete aggregate mix (Mix-1) and recycled stone base mix (Mix-2) are presented in Fig. 5. Table 5 shows assess the significance influence (two-way ANOVA) of the tested factors (type, amount) on the distribution of the tested parameters.

(a)

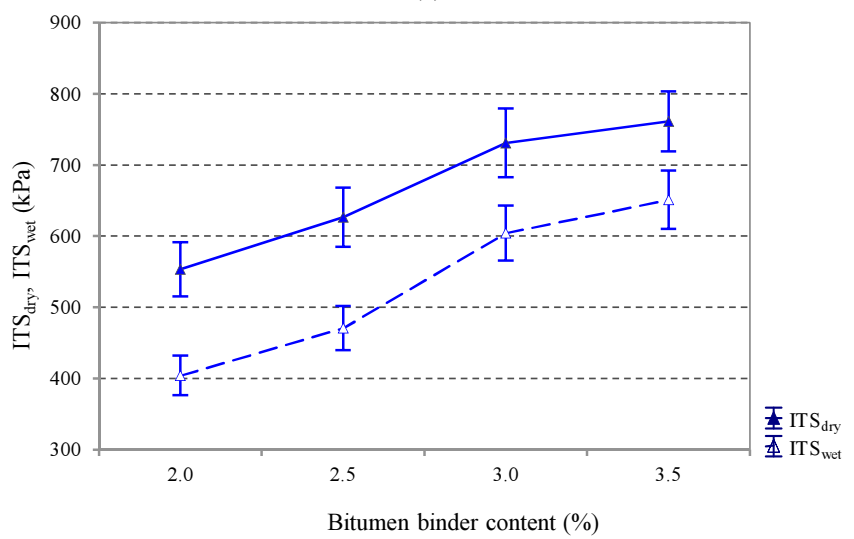

(b)

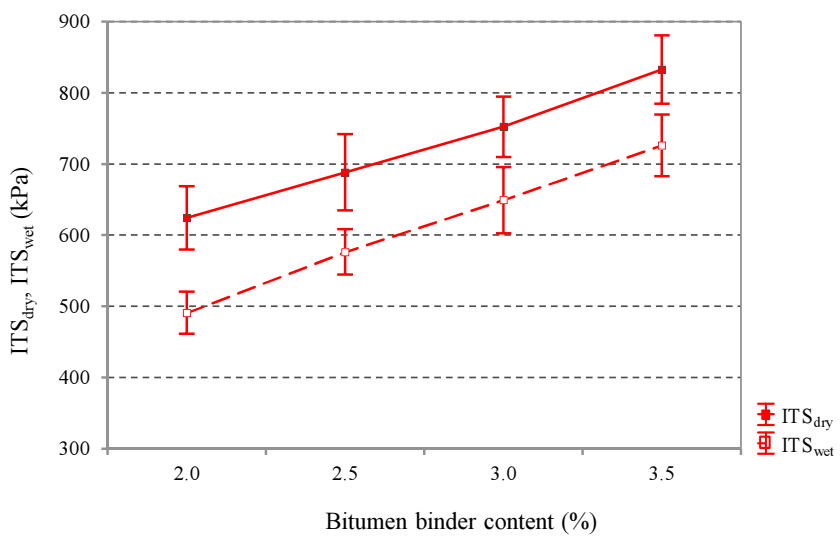

Fig. 4. Relationship between indirect tensile strengths before $\left(I T S_{d r v}\right)$ and after soaking $\left(I T S_{w e t}\right)$ and amount of foamed bitumen in road base Mix-1 (a) and Mix-2 (b)

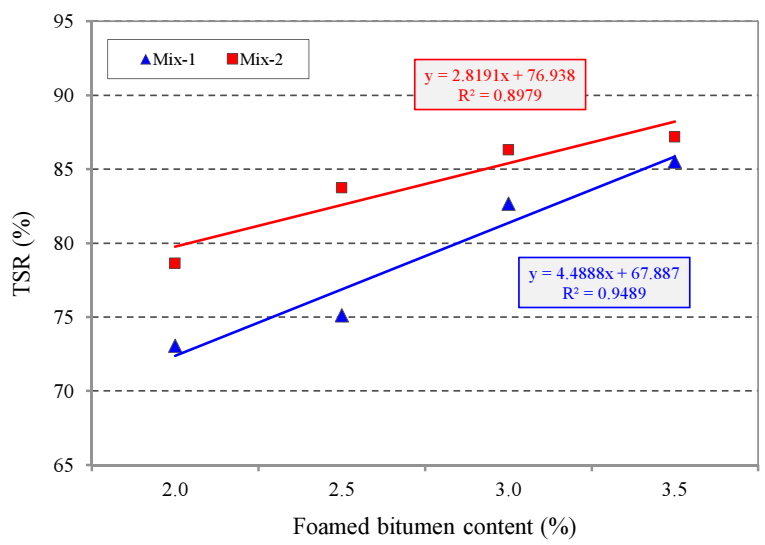

Fig. 5. Foamed bitumen content versus tensile strength retained (TSR) of road base mixtures 
The analysis of the test results presented above indicates that the moisture resistance of the road base with foamed bitumen was significantly affected by the type of the recycled material derived from the existing pavement layers, and by the amount of the foamed bitumen added to the road base mixtures. The increase in the foamed bitumen content entailed the increase of the mechanical parameters being tested, that is, the resistance to the detrimental climatic factor (moisture) was improved.

The mixes containing the crushed stone base had lower ITS $S_{d r y}$ values than mixes with recycled lean concrete. All the mixes in the tests had greater than the recommended minimum value of $225 \mathrm{kPa}$ [10], [15].

The indirect tensile strength values of all the mixes after curing in water were greater than the required minimum value of $100 \mathrm{kPa}$, as specified in [10], [15]. The recycled road base with recycled lean concrete aggregate showed slightly higher values of ITS wet $_{\text {than }}$ the one with recycled crushed stone aggregate did.

The evaluation of the mean values of TSR indicates that all the road base mixes were resistance to the detrimental action of water, because TSR ratio was higher than the minimum value (70\%) recommended by the TG2 guidelines [24]. A higher moisture resistance was recorded for the mixes with the reclaimed crushed lean concrete. Linear functions, which explain more than $94 \%$ and $89 \%$ of the total variance, were used to describe the relationship between the resistance to water TSR and foamed bitumen content for both mixes (Mix 1, Mix 2).

Summarizing, the tests revealed that the road base produced in the cold recycling technology, with foamed bitumen and aggregates from the recycled lean concrete waste had better mechanical parameters $\left(I T S_{d r y}, I T S_{w e t}\right)$ and the higher moisture resistance (TSR) compared to the mixes with recycled stone road base.

Table 5. Two-way (ANOVA) analysis of variance

\begin{tabular}{lllllll}
\hline Feature & ITS dry & & ITS & & TSR & \\
\hline Source & Type & Amount & Type & Amount & Type & Amount \\
\hline Degrees of freedom & 1 & 3 & 1 & 3 & 1 & 3 \\
Sum of squares & 4439.48940 & 472021.002 & 77591.7356 & 641013.533 & 0.11520 & 0.13050 \\
Mean of squares & 4439.48940 & 157340.334 & 77591.7356 & 213671.178 & 0.11520 & 0.04350 \\
F Ratio & 1.26 & 44.70 & 36.59 & 100.76 & 952.89 & 359.81 \\
$p$-value & 0.2654 & $<0.0001$ & $<0.0001$ & $<0.0001$ & $<0.0001$ & $<0.0001$ \\
\hline
\end{tabular}

Results of the two-way ANOVA revealed the significant effect ( $p$-value $<0.0001)$ of the kind of the recycled aggregates in the road base mixes and content of foamed bitumen on change features $\left(I T S_{w e t}, T S R\right)$ in the experimental range of $2.0 \%$ to $3.5 \%$. Whereas there was no significant effect of tested factor (type) on the change in the ITS $S_{d r y}(p$-value $=0.2654)$. It can be state that the type of the recycled aggregates used in the road base mixes did not have a significant impact on the distribution of the tested parameter.

\subsection{Indirect tensile stiffness modulus}

Stiffness of the bituminous materials can be measured using the indirect tensile stiffness (ITSM) test, which is a nondestructive method. The stiffness modulus expresses the relationship of stress and strain at a certain temperature and load. In addition, the visco-elastic characteristics are contained in the expression of stiffness modulus [25]. Foamed bitumen stabilization increases the stiffness modulus value of the mix compared to the unbound material. The moduli of foam treated materials are generally lower than those of hot mix asphalt [26], but can approach or exceed those of lime or cement treated materials [27]. The Universal Testing Machine (UTM-25) was utilized for determining the stiffness modulus of cylindrical specimens accordance with European standard EN 12697-26. In this lab study stiffness modulus was testing in indirect shear scheme (IT-CY) with the following settings: test temperature: $25^{\circ} \mathrm{C}$, rise time: $124 \pm 4 \mathrm{~ms}$, horizontal deformation: $5 \mu \mathrm{m}$ and Poisson's ratio: 0.35 .

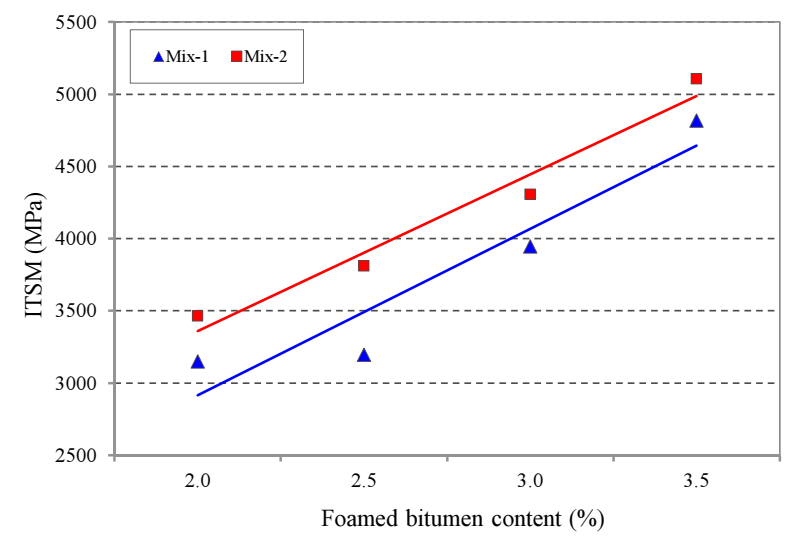

Table 6. Evaluation of significant influence (two-way ANOVA) of the factors on the $R M$ feature

\begin{tabular}{lll}
\hline Source & Type & Amount \\
\hline Degrees of freedom & 1 & 3 \\
Sum of squares & 6142342.60 & 2188102.80 \\
Mean of squares & 6142342.60 & 729367.600 \\
F Ratio & 18.57 & 1.789 \\
$p$-value & $<0.0001$ & $<0.0001$ \\
\hline
\end{tabular}




\begin{tabular}{ccc} 
Type of mixture & Linear regression & $\mathrm{R}^{2}$ \\
\hline Mix-1 & $\mathrm{y}=542.60 \mathrm{x}+2818.1$ & 0.9659 \\
Mix-2 & $\mathrm{y}=576.09 \mathrm{x}+2339.2$ & 0.8985 \\
\multicolumn{2}{c}{ Note: $y$-RM, $x$-foamed bitumen content }
\end{tabular}

Fig. 6. Foamed bitumen content versus indirect tensile stiffness modulus (ITSM) of road base mixtures

The analysis of the results from the stiffness modulus tests indicates that the increase in the foamed bitumen regardless of the recycled aggregate type used in the mixes results in the increase of the parameter being tested. Road base mixes containing materials from the crushed lean concrete had a higher stiffness modulus compared with the mixes with the recycled crushed stone aggregate.

According to Wirtgen Cold Recycling Manual [28], the stiffness modulus of the recycled mixes with foamed bitumen should range from $2500 \mathrm{MPa}$ to $4000 \mathrm{MPa}$. The road base mixtures with foamed bitumen content in the range of $2.0 \%$ to $3.0 \%$ reach required values for this type of the mineral material (50:50 RAP/crushed stone blend).

The road base produced in cold recycling with foamed bitumen containing reclaimed crushed lean concrete had the higher stiffness modulus than that of the road base with crushed stone. In the recycled mixtures (Mix-1, Mix-2) with 3.5\% foamed bitumen content, the $R M$ parameter exceeded the maximum recommended value (4000 MPa).

A linear function was used to describe the relationship between the stiffness modulus and the foamed bitumen content in the tested mixtures. The values of $\mathrm{R}^{2}$ for both mixes were more than 0.90 , which indicates that more than $90 \%$ variation was explained by the estimated function.

The results of the Analysis of variance of the tested parameter proves that the amounts of both factors have an important impact on stiffness modulus of the recycled road base materials. Results, at significance level of 0.05 , revealed the significant influence of the type of the recycled aggregates and amount of foamed bitumen on changes of $R M$ parameter (pvalue $<0.001$ ) in the experimental range of $2.0 \%$ to $3.5 \%$.

\section{Conclusion}

Based on the analysis of the test results of the recycled base with foamed bitumen, the following conclusions can be drawn:

- the type of the recycled aggregate as well as the amount of bituminous binder (foamed bitumen) affects the properties of the recycled road base;

- the increase of the foamed bitumen content in the recycled material to $2.5 \%$ improves its Marshall stability; the further increase in the amount of foamed bitumen causes a decreasing of this parameter;

- the indirect tensile strength $\left(I T S_{d r y}, I T S_{w e t}\right)$ of the road base materials increases with the increase in foamed bitumen content in the recycled mixtures;

- moisture susceptibility in terms of a tensile strength ratio (TSR) was higher than the minimum value required for road base mixtures, which means that they satisfied the basic criterion set for the resistance to the action of water;

- mechanical parameters and moisture resistance of foamed bitumen mixes with reclaimed crushed lean concrete were considerably higher than of the mixes containing crushed stone base layer;

- the foamed bitumen content and kind of the recycled aggregates in the mixtures have a significant influence on the changes of the stiffness modulus at $25^{\circ} \mathrm{C}$; the values of $R M$ increased when the bitumen binder content rised;

- the two-way factorial analysis of variance revealed a significant effect of the type of the recycled aggregates and amount of foamed bitumen on the properties of the recycled road base;

- the addition of $2.5 \%$ foamed bitumen and $2.0 \%$ Portland cement to the recycled road base materials results in ensuring their most advantageous mechanical characteristics;

- the RAP content of $48 \%$ has a positive influence on the road base resistance to moisture ensuring proper stiffness and durability to deformation at the same time;

- the foamed bitumen treated road base mixes that incorporate recycled crushed lean concrete guarantee better parameters in terms of moisture resistance compared with to the mixes containing material from the crushed stone base layer.

\section{Acknowledgements}

The scientific research has been carried out as o part of the Project "Innovative recourses and effective methods of safety improvement and durability of buildings and transport infrastructure in the sustainable development" (No POIG 01.01.0210-106/09-01) financed by the European Union from the European Fund of Regional Development based on the Operational Program of the Innovative Economy. 


\section{References}

[1] Żygadło, M.; Orman, Ł. 2008. Możliwości odzysku energii w procesie mechaniczno - biologicznej przeróbki odpadów komunalnych, in Proc of XIV Conf. „Rynek Ciepła - REC 2008”, 159 -166. Nałęczów - Lublin.

[2] Vaitkus, A.; Cygas, D. 2009. Analysis and evaluation of possibilities for the use of warm mix asphalt in Lithuania, The Baltic Journal of Road and Bridge Engineering 4(2): 80-86. http://dx.doi.org/10.3846/1822-427X.2009.4.80-86

[3] He, G.; Wong, W. 2008. Effects of moisture on strength and permanent deformation of foamed asphalt mix incorporating RAP materials, Elsevier: Construction and Building Materials 22(1): 30-40. http://dx.doi.org/10.1016/j.conbuildmat.2006.06.033

[4] Saleh, M. F. 2007. Cost evaluation of foam bitumen and other stabilization alternatives, Taylor and Francis: International Journal of Pavement Engineering 8(2): 157-161. http://dx.doi.org/10.1080/10298430601149585

[5] Grabowski, W.; Janowski, L.; Wilanowicz, J. 2013. Problems of energy reduction during the hot-mix asphalt production, The Baltic Journal of Road and Bridge Engineering 8(1): 40-47. http://dx.doi.org/10.3846/bjrbe.2013.06

[6] Radziszewski, P.; Piłat, J.; Kowalski, K.; Król, J. 2012. Use of Aggregate from Glacier Deposits in High-Traffic Asphalt Pavements: a Polish Experience, The Baltic Journal of Road and Bridge Engineering 7(1): 5-12. http://dx.doi.org/10.3846/bjrbe.2013.06

[7] Mallick, R. B.; Hendrix, G. 2004. Use of foamed asphalt in recycling incinerator ash for construction of stabilized base course, Elsevier: Resources, Conservation and Recycling 42(3): 239-248. http://dx.doi.org/10.1016/j.resconrec.2004.04.007

[8] Kim, Y.; Lee, H. D.; Heitzman, M. 2009. Dynamic Modulus and Repeated Load Tests of Cold In-Place Recycling Mixtures Using Foamed Asphalt, Journal of Materials in Civil Engineering 21(6): 279-285. http://dx.doi.org/10.1061/(ASCE)0899-1561(2009)21:6(279)

[9] Saleh, M. F. 2007. Cost evaluation of foam bitumen and other stabilization alternatives. International Journal of Pavement Engineering 8(2), Taylor and Francis, 157-161. http://dx.doi.org/10.1080/10298430601149585

[10] Asphalt Academy. 2009. Technical Guideline: Bitumen Stabilised Materials, A Guideline for the Design and Construction of Bitumen Emulsion and Foamed Bitumen Stabilised Materials, Technical Gudeline 2 (TG2) [online], Available from Internet: http://www.asphaltacademy.co.za/Documents/TG2May09.pdf

[11] Brown, S. F.; Needham, D. 2000. A study of cement modified bitumen emulsion mixtures, Journal of the Association of Asphalt Paving Technologists Vol. 69, Reno, Nevada, USA.

[12] Hodgkinson, A.; Visser, A. T. 2004. The role of fillers and cementitious binders when recycling with foamed bitumen or bitumen emulsion, in Proceedings of the8th Conference on Asphalt Pavements for Southern Africa, Sun City, South Africa, 2004.

[13] Jian, X.; Songchang, H.; Yougchun, Q.; Feng, L. Impact of cement content on properties of foamed asphalt cold recycling mixtures, in 10th Conference on asphalt pavements for southern Africa.

[14] Warunki techniczne wykonywania warstw podbudowy z mieszanki mineralno-cementowo-emulsyjnej (MCE) [Technical Requirements for the Construction of Base Course Layers with mineral-cement-emulsion Mixes (MCE)], Vol. 61, Instytut Badawczy Dróg i Mostów (IBDiM) [Road and Bridge Research Institute], 1999.

[15] Wirtgen. 2012. Wirtgen Cold Recycling Technology [online], Wirtgen GmbH, Windhagen: Germany, 2012. Available from Internet: http://www.wirtgen.de/media/redaktion/pdf-dokumente/03_kaltrecycling_stabilisierung/_allgemein_1/manual/p_manual_e.pdf

[16] Van de Ven, M. F. C.; Jenkins, K. J.; Voskuilen, J. L. M.; Van Den Beemt, R. 2007. Development of (Half-) Warm Foamed Bitumen Mixes: State of the Art, International Journal of Pavement Engineering 8(2): 163-175. http://dx.doi.org/10.1080/10298430601149635

[17] Jenkins, K. J.; Long, F. M.; Ebels, L. J. 2007. Foamed bitumen mixes = shear performance?, International Journal of Pavement Engineering 8(2): 8598. http://dx.doi.org/10.1080/10298430601149718

[18] Jenkins, K. J. 2000. Mix Design Considerations for Cold and Half warm Bituminous Mixes with emphasis on Foamed Bitumen. PhD Dissertation 2006. University of Stellenbosch. South Africa. 368 p.

[19] Iwański, M.; Chomicz-Kowalska, A. 2012. Moisture and frost resistance of the recycled base rehabilitated with the foamed bitumen technology, Archives of Civil Engineering 58(2): 185-198. http://dx.doi.org/10.2478/v.10169-012-0011-2

[20] Iwański, M.; Chomicz-Kowalska, A. 2013. Laboratory Study on mechanical Parameters of Foamed Bitumen Mixtures in the Cold Recycling Technology, [USB-stick], in Proc. of the 11th International Conference "Modern Building Materials, Structures and Techniques". May 16-17, 2013, Vilnius, Lithuania. Procedia Engineering 57, Elsevier: 433-442. http://dx.doi.org/10.1016/j.proeng.2013.04.056

[21] Bissada, A. F. 1987. Structural Response of Foamed-Asphalt-Sand Mixtures in Hot Environments, Asphalt materials and mixtures, Washington, DC: Transportation Research Board 1115, 134-149. Available from Internet: http://asphalt.csir.co.za/FArefs/Bissada.pdf

[22] Jaskuła, P.; Judycki, J. 2008. Verification of the criteria for evaluation of water and frost resistance of asphalt concrete, Road Materials and Pavement Design 9: 135-162. http://dx.doi.org/10.1080/14680629.2008.9690163

[23]Muthen, K. M. 1998. Foamed Asphalt Mixes - Mix Design Procedure. Contract Report No. CR-98/077, SABITA and CSIR Transportek, Pretoria, South Africa.

[24] Asphalt Academy, Interim Technical Guidelines (TG2): The Design and Use of Foamed Bitumen Treated Materials [online]. CSIR, Pretoria, South Africa, June 2002.

[25] Yan, J.; Ni, F.; Yang, M.; Li, J. 2010. An experimental study on fatigue properties of emulsion and foam cold recycled mixes, Taylor and Francis: Construction and Building Materials 24, 2151-2156. http://dx.doi.org/10.1016/j.conbuildmat.2010.04.044

[26] Loizos, A.; Papavasiliou, V. 2006. Estimation of certain foamed asphalt layer properties of cold in-place recycling, 85th Annual Meeting of Transportation Research Board, CD compendium.

[27] Sakr, H. A. \& Manke, P.G. 1999. Innovations in Oklahoma Foamix Design Procedures, Asphalt materials, mixes, construction and quality, Washington, DC: Transportation Research Board 1034: 26-34.

[28] Wirtgen. 2004. Wirtgen Cold Recycling Manual [online], Wirtgen GmbH, Windhagen: Germany, November 2004. Available from Internet: http://www.resansil.com/english/images/wirtgen/cold_recycling.pdf 